\title{
Constructing the Curriculum System of Cultivating High - end Skilled Talents through Secondary Vocational Education and Undergraduate Teaching
}

\author{
Xiaoling Wei ${ }^{1, a^{*}}$, Zijing Hou ${ }^{1, b}$ and Wenju $\mathrm{Li}^{1, \mathrm{c}}$ \\ ${ }^{1}$ College of Mechanical and Equipment Engineering, Hebei University of Engineering, Hebei, \\ Handan 056038
}

awxlcsm@163.com,,2419457917@qq.com,,2261823810@qq.com

\begin{abstract}
Key words: Curriculum system; Cohesion strategy; Monitoring system; Piecewise training
\end{abstract}
\begin{abstract}
The core and key of cultivating the high-end technical and technical talents are the convergence of the curriculum system. This paper analyzes the effect on construction of curriculum system about mechanical design and manufacturing automation, problems existing in the process of curriculum system convergence, principles and strategies for the construction of curriculum system. This paper puts forward the construction of modular curriculum system, which is "To the convergence of secondary vocational schools and the ability cultivation as the core" .In order to achieve the smooth progress of curriculum system construction, this paper puts forward some measures such as strengthening the construction of teaching staff, strengthening the construction of practical teaching base, establishing reasonable teaching evaluation and supervision system, to guarantee the effect and quality of teaching.
\end{abstract}

\section{The Role of Bridging Course System Construction on Secondary Vocational Undergraduate Level Machine Machinery Manufacturing Professional}

At present, the biggest problem in China's talent level is the serious shortage of applied technology high quality skilled talents, which has become the bottleneck restricting the development of our country's economy. It is urgent to cultivate professional and technical talents to meet the needs of social development. In response to the Ministry of Education, "on the promotion of higher vocational education reform and innovation to lead the development of vocational education in a number of opinions" [1], in order to solve the shortage of skilled technical personnel problems in current, since 2014, Hebei Province has established talent training mode adapted to modern education system ,such as " $3+3$ " "3 + 4" .Our school with Shijiazhuang Engineering School and Chengde Industrial Engineering School carried out mechanical design and manufacturing and its automation (mechanical engineering) " $3+4$ " segmented pilot projects for people to cultivate undergraduate level. Carrying out " $3+4$ " is necessary to adjust the structure of education, to meet the needs of the transformation and upgrading of social industry and the development of science and technology. It is the most effective way to solve the problem of talent shortage. At present, because the secondary vocational education and the undergraduate education belong to two different stages, in the aspect of teaching organization and management is different, in the process of training target and curriculum system cohesion will be not tight, teaching organization and operation and management convergence and other issues. Therefore, the effective convergence of secondary vocational colleges is the key to the success or failure of personnel training. As an important content of secondary vocational undergraduate cohesion, curriculum system construction is secondary vocational undergraduate talents training target and reflect the embodiment of social demand and the effective carrier. It is very important to establish a modular curriculum system with clear objectives, reasonable structure, precise convergence and progressive ability. Combining the knowledge, ability and quality in the course system is very important for ensuring the organic convergence of curriculum system and improving the quality of personnel training. 


\section{The Problems in Bridging Course System Construction on Secondary Vocational Undergraduate Level Machine Machinery Manufacturing Professional}

The core task of cultivating application-oriented high-end technical and technical talents is to set up and implement the curriculum. As the training process is divided into sections, the curriculum objectives, course structure, course content and job ability training are formulated and implemented by the schools separately. There is no effective communication and communication between schools and teachers, and cannot carry on the connection of curriculum system from the whole point of view. The concrete manifestation is as follows: the orientation of the curriculum objectives between the vocational and undergraduate is not clear, no cohesive mechanism for the development of curriculum standards. Between secondary and undergraduate course, repeat setting and lack of content, lack of gradation course on content choice, unclear teaching boundary, leaky cohesion; teaching content and professional direction are not allowed to segment, the difficulty , the depth and breadth of the distinction about teaching the curriculum is are not clear[2], on the one hand, professional foundation course content in the professional beyond the scope of the task, the task is heavy, difficult ,which lead students to keep up with the progress of the curriculum uncomfortably, resulting in weariness, on the other hand ,the basic courses and professional basic courses have less learning content and insufficient depth, which cannot be connected with the basic courses and professional courses in the latter stage, which seriously affect the enthusiasm and effect of students' learning. Such as "mechanical drawing", "circuit theory", "mechanical design basis", "engineering mechanics", "electronic technology" ,these courses have repeated with undergraduate courses, if not clear secondary vocational undergraduate course teaching content and the ability training requirements, cannot achieve the hierarchy of contents of courses, continuity, and consistency, the knowledge ability of students can't adapt to the requirement of professional post, cohesive segment is difficult to achieve the purpose of training high-level technical skills talents.

\section{Linking Strategy of Bridging Course System Construction on Secondary Vocational Undergraduate Level Machine Machinery Manufacturing Professional}

The Principle of Curriculum System. The basic purpose of the combination of secondary vocational school and undergraduate course is to cultivate high-level technical and technical talents at the undergraduate level. Therefore, the convergence of curriculum system must adhere to the principle of ability cultivation as the core; in order to train personnel constantly adapt to the need of economic structural adjustment and industrial transformation and upgrading, through secondary education and training of undergraduate level, to achieve the overall upgrade and deepening on skills and quality; curriculum system convergence must reflect the market demand-oriented and flexible principles, curriculum objectives should not only correspond to professional positions but also to adapt to changes in job requirements; must deal with the principle of combining theory with practice, the secondary vocational undergraduate course as the two important stages of the teaching process, the theoretical knowledge and practical skills are two indispensable content, must handle the relationship between the knowledge and skills, emphasis on theoretical teaching much, while ignore or neglect practical teaching is not desirable; curriculum system connection must be geared to the needs of market, the cultivation of technical and technical talents emphasize the training of post practical ability, must follow the principle of work-integrated learning, university-enterprise cooperation[3], through the exercise of manufacturing, achieve the cultivation of the students' knowledge, skills, and quality improving.

\section{The Strategy of Constructing the Curriculum System.}

1. Constructing the Modular Curriculum System of "Secondary Vocational Undergraduate Cohesion, Ability Training as the Core". The basic task of the course system construction is to make the effective connection of the curriculum, including the connection of the course setting, of the course content, of the teaching materials and the cultivation of the practical skills. The 
curriculum system is set to take full account of the characteristics of secondary vocational education and teaching resources, learn from each other, the full implementation of the " $3+4$ " seven-year system through the sub-training of personnel objectives. For advanced manufacturing technology position group, set up the public basic courses, professional basic courses, professional direction courses, professional development courses and professional skills training courses. Public basic course guarantee secondary vocational undergraduate students basic scientific literacy, laying the foundation for professional learning and lifelong development; professional basic course and professional direction course pays attention to the cultivation of students' professional ability and the quality, the direction of professional development course focuses on the cultivation of students' thinking ability and innovation ability, professional skills training emphasizes students from a single post to exercise comprehensive skills. In the process of curriculum design, the stage of the secondary vocational school emphasizes the solid foundation of students 'knowledge, strong practical ability, and possesses certain professional qualities, the undergraduate course emphasizes the academic, theoretical, hierarchical and systematic nature of students' theoretical knowledge[4].In the course of teaching, the middle and vocational level adopt the project-based, case-based modular teaching, and the undergraduate course adopts the guidance-oriented and inquiry-based curriculum. Course structure emphasizes the overall design, co-ordination arrangements, effective convergence and the implementation of sub-ideas. The teaching content should set clear, reasonable, distinct course standard, to ensure students learn knowledge with continuity and acceptability. The core curriculum is based on the knowledge and ability as the main line, highlights the basic position of the secondary vocational school, emphasizes the expansion and deepens the undergraduate course, strengthens the internal logic of the cultivation of high-end technical and technical talents of machinery manufacturing, reflects consistency of piecewise culture cohesion [5].In the modular curriculum teaching, the first three years in the vocational stage, give priority to the basic course module, cultivate students' lifelong learning ability and sustainable development ability. After four years of undergraduate course, set up the basic ability of the professional curriculum modules, specialized special ability curriculum module, professional comprehensive ability curriculum module, highlight the technical and management ability. Practical skills training are an important guarantee for the construction of curriculum system. The curriculum module of professional comprehensive ability mainly involves practical teaching, including basic skills training, special skills training, professional skills comprehensive training and internship, focusing on strengthening students analysis, problem-solving ability. Professional skill integrated training stage pay more attention to the cultivation of the students' comprehensive practical ability, vocational ability, and Integrate quality, knowledge and skills. Enterprise internship stage is to take test in the practical skills of students in front of three stages, make students get real enterprise temper on professional skills, lay a solid foundation for future employment. In professional positions for the joining of technical ability training, emphasis on the cultivation from a single skill to a comprehensive skills during the secondary and undergraduate through progressive, relying on the depth of school-enterprise cooperation to improve students practical ability, problem analysis ability and job adaptability. Build a unified system of professional qualification certificate, realize the profession overall cohesion, to lay a foundation for the improvement of students' comprehensive quality, professional ability formation and the sustainable development [6].In order to effectively ensure the implementation of practical teaching module, we should set up a special practice project team, responsible for the docking and implementation of the project, organizing and managing the practical teaching, responsible for the development of practice curriculum system and solving the problems in practice teaching, practice teaching quality monitoring, strengthen the process management, fully arouse the enthusiasm of students' learning.

2. Pay Attention to the Professional Construction of Teaching Material, Improve the Teaching Effect and Quality. The form of curriculum system cohesion is the rationality of the textbooks and the convergence of teaching content. For secondary vocational undergraduate cohesion training high-end technical skills talents, it is different from higher vocational teaching and applied undergraduate teaching, it is the form of teaching derived from vocational education 
and higher than the vocational education, emphasis on the cultivation of students' professional ability and quality, the selection of teaching material cannot continue to use higher vocational teaching material nor overemphasize the undergraduate course teaching material again. Therefore, according to the curriculum design standards, clarify the teaching requirements of secondary vocational schools, strengthen teachers' communication and exchanges of partner institutions, to carry out inter-provincial school and school, school and enterprise cooperation, conduct the test book writing with characteristics. According to the content of secondary and undergraduate test book write boundaries, to avoid the repetition and lack of the teaching material content; reconstruct teaching modules according to the course content, orchestrate the teaching material content with the ease of modules, arrange the required theoretical knowledge reasonable ; attach great importance to the integration and innovation of teaching material, decisively remove difficult, useless, repetitive material content, update the outdated, integrate similar ,supplement the advanced, refine the key to retain the core content of the textbook. The construction of characteristic building materials can meet the basic requirements of the secondary vocational school curriculum and the need of continuing learning in the undergraduate course, so as to improve the teaching effect and quality.

\section{Safeguards of Cohesion of Curriculum System in Secondary Vocational School}

Strengthen the Construction of Teachers Team. According to the teaching characteristics of " $3+$ 4", we should formulate relevant policies, encourage both teachers to strengthen the connection, establish the mutual exchange system between teachers and teachers, and select excellent teachers to serve as teaching tasks and business guidance in secondary vocational schools. Vocational teachers arranged to colleges and universities to guide students to learn from each other, to achieve cooperation in the sharing of teacher's resources. Establish the "double-type" professional teacher's team; cultivate outstanding teachers with engineering practice ability and a higher theoretical level, meet student's need of the professional knowledge and practical skills. Professional teacher should have strong ability and high professional qualification, play lead roles in the professional reform and development. Teacher's professional ability should adapt to the needs of industry and enterprise development, understand the status of enterprise development, use holidays and spare time to participate in business practice and technical services, improve their ability in practice. Employ the technical personnel with more than senior professional qualifications and professional titles in industry and trade enterprises as part-time teachers; participate in school training program development, curriculum system construction, professional courses, students training guidance, science and technology preface lectures and other teaching activities. To ensure the smooth implementation of bridging curriculum system.

Strengthen the Construction of Teaching Base. High-end technical and technical personnel training process must be combined with the actual production of industry and enterprises, any professional ability cannot be separated from the real production environment. Students will go through seven years of uninterrupted experiment, practice, training and job skills training to complete vocational training from the beginning to the end of the undergraduate study, whether vocational or undergraduate schools cannot have a complete practical skills training surroundings. To ensure that students possess solid skilled professional skills, solid professional foundation, must strengthen the practice teaching base construction inside and outside the school building. On the basis of perfecting the internal training environment, expand the construction of the training base outside the university and rely on the high-quality equipment and human resources of the enterprises. Gradually form a comprehensive teaching and training base integrating production, learning and research, improve the students' practical skills and the adaptability of the working environment to protect the quality of technical and technical personnel training.

Constructing the Evaluation Regulation System of Technical Talents. Secondary vocational particularity determining the evaluation of students' assessment is different from the students in vocational and undergraduate students. In addition to the sub-examination and unified examination results, should pay attention to the usual results; including classroom performance, job completion, 
school discipline, laboratory operation ability and other achievements. Professional course study should combine the process evaluation and evaluation of the final exam. Comprehensive ability evaluation adopts project assessment method, according to the accuracy and proficiency of students to complete the task assessment results. To reflect the students' technical skills level, give full consideration to the students' innovative, pioneering and creative thinking ability. In order to ensure the smooth progress of curriculum convergence, should set up the reasonable access mechanism for secondary to undergraduate students, set clear requirements and standards of turn period, students cannot meet the turn paragraph condition can also not enter the undergraduate stage of study, supply appropriate learning pressure for stage students, to avoid students cannot keep up with follow-up study, result in slackness and weariness. In order to improve the social recognition of personnel training, absorb industry enterprises to participate in the training process monitoring, treat the employment rate of graduates, enterprise satisfaction as an important index to measure the quality of personnel training, and establish a teaching quality evaluation system with the participation of a school, social. Visits the employer regularly and establish good communication and communication channels, listen to business advice and suggestions, and constantly improve the convergence of course system. Set up a practice and innovation training base about college students and lead the students to actively participate various skills contest, establish competition incentive system[7-10], arouse the enthusiasm of students learning, cultivate the students' ability and comprehensive quality all-round way, to ensure that" $3+4$ "sub-training technical personnel skills to achieve smoothly.

\section{Acknowledgements}

[Fund Project] 2016 Hebei Province Higher Education Teaching Reform Research and Practice Project (ID: 2016GJJG125).

\section{Literature References}

[1] Q.h.Song and X.W.Li, Education and Occupation, (2014) NO.12, p.26-28, (In Chinese).

[2] C.R.Yang, Journal of Wuhan Institute of Communications, (2015), NO.4, p.59-41, (In Chinese).

[3] P.Xue and X.R.Hu,Office Automation, (2016),NO.1,p. 32-34,(In Chinese).

[4] W.K.Wang and H.X.Peng, Contemporary Vocational Education, (2016), NO.3, p.25-27, (In Chinese).

[5] Y.Zhang and L.Li,Journal of Continuing Education Research, (2014),NO.4,p.121-123,(In Chinese).

[6] W.H.Xuan,M.H.Li and X.Zuo etc. Journal of Jinling Institute of Technology Study, Vol.29 (2015) NO.2, p. 76-78, (In Chinese).

[7] X.L.Wei and Z.H.Fan, Hebei University of Engineering Social Science Edition, Vol.32 (2015) NO.4, p.92-94,(In Chinese).

[8] J. Mi: China Electric Power Education, (2011) No. 25. p. 148-149, (In Chinese).

[9] X.L. Wei, B.G. Zhang and J.F. Wang: Journal of Hebei University of Engineering (Social Science Edition), Vol 31 (2014) No. 2. p. 80-82, (In Chinese).

[10] X.Z. Ming, C.L. Tang and J.P. Wu: Experiment Science and Technology, Vol 9 (2011) No. 6. p. 157-160, (In Chinese). 